\title{
The Saudi Healthcare System: A View from the Minaret
}

Amir A. Khaliq, PhD, MBBS, MSHS, MSc, Associate Professor Health Administration \& Policy, College of Public Health, University of Oklahoma Health Sciences Center, Oklahoma City, Oklahoma

Correspondence may be directed to: Amir A. Khaliq, Health Administration \& Policy, College of Public Health, University of Oklahoma Health Sciences Center, Oklahoma City, Oklahoma, Tel: (405) 271-2114 X 5, E-mail: amir-khaliq@ouhsc.edu

\begin{abstract}
This review article provides information about the origins, history, evolution and current status of the Saudi healthcare system, which is currently being transformed from a publicly financed and managed welfare system to a market-oriented, employment-based, insurance-driven system. Since its inception in the 1920s, the system has provided free healthcare to all Saudi nationals at publicly owned facilities run by government-employed administrators and healthcare providers. For millions of foreign workers in the country, healthcare at privately owned for-profit facilities has been paid for either by the employer or by the individual. At the completion of the three-stage transition, everyone in the country, whether employed in the public or private sector, is expected to have insurance coverage provided by the employer. All Ministry of Health-owned hospitals will be divested to the private sector, whereas primary health centres are likely to be retained by the government. Many of the operational details of the transition are unclear at this stage and will be worked out in the coming years. This paper provides a context for these changes and highlights some of the existing issues and weaknesses. The article also points to some of the future challenges and cautions against pitfalls involved in the complete transformation of the system.
\end{abstract}

\section{Country Profile ${ }^{1}$}

In the past 50 years, Saudi Arabia, the largest of the Middle Eastern countries, with a land mass of 2.0 million square kilometres (Table 1), has been transformed from a nation with a relatively small nomadic, rural population of less than four million to one of the most urbanized societies in the Middle East. Saudi Arabia's total population is now about 26 million, of which more than 85\% reside in a few urban centres. In 2009, the capital city of Riyadh and its surrounding areas alone accounted for more than 6.2 million people (United Nations Development Program [UNDP] 2010; United Nations Children's Fund [UNICEF] 2011; World Bank 2010; World Health Organization [WHO] 2010a). The current estimate of population growth is about $2.2 \%$ per year, and, by 2020 , the population is expected to reach 31.6 million (UNDP 2010; World Bank 2010). In 1960, only $1.6 \%(63,400)$ of the population comprised non-Saudis (Metz 1992; UNDP 2009), but in 2005, fully $26.8 \%$ (6.33 million) consisted of non-Saudis, of which a vast majority (69.9\%) were men (Ministry of Health [MOH] 2009). 
Table 1. Demographic, economic and health related data for Saudi Arabia and five other countries in the region ${ }^{\text {a }}$

\begin{tabular}{|c|c|c|c|c|c|c|}
\hline & $\begin{array}{c}\text { Saudi } \\
\text { Arabia }\end{array}$ & Kuwait & Egypt & Jordan & Libya & Oman \\
\hline Area in square kilometres & $2.0 \mathrm{~m}$ & 17,818 & $1.0 \mathrm{~m}$ & 91,880 & $1.76 \mathrm{~m}$ & 309,500 \\
\hline Total population in millions & 25.4 & 2.4 & 82.0 & 5.3 & 5.3 & 2.5 \\
\hline Population growth rate & $2.2 \%$ & $3.3 \%$ & $2.0 \%$ & $2.5 \%$ & $1.8 \%$ & $2.2 \%$ \\
\hline Population under 15 years of age & $35 \%$ & $23.7 \%$ & $37.4 \%$ & $37.1 \%$ & $32.0 \%$ & $38.9 \%$ \\
\hline Adult literacy rate & $88 \%$ & $90.9 \%$ & $69.4 \%$ & $90.9 \%$ & $86 \%$ & $78 \%$ \\
\hline GDP per capita (current $\$$ ) & $\$ 18,603$ & $\$ 15,984$ & $\$ 1,036$ & $\$ 2,103$ & $\$ 5,128$ & $\$ 12,239$ \\
\hline Expenditure on health as \% of GDP & $3.3 \%$ & $3.8 \%$ & $3.7 \%$ & $10.4 \%$ & $3.3 \%$ & $2.8 \%$ \\
\hline Health expenditure per capita & $\$ 621$ & $\$ 552$ & $\$ 192$ & $\$ 188$ & $\$ 222$ & $\$ 340$ \\
\hline Out-of-pocket spending as $\%$ of total health expenditure & - & - & $61 \%$ & $9 \%$ & $23 \%$ & $9.1 \%$ \\
\hline$\%$ of population with access to safe drinking water & $97 \%$ & $100 \%$ & $91.3 \%$ & $95.1 \%$ & 98.45 & $75 \%$ \\
\hline Life expectance at birth (in years) & 73.4 & 78.7 & 70.1 & 71.4 & 69.0 & 74.3 \\
\hline Infant mortality per 1000 live births & 17.4 & 9.4 & 20.5 & 22 & 24 & 10.3 \\
\hline Maternal mortality 100,000 births & 14 & 9.1 & 63 & 40 & 51 & 15.4 \\
\hline Total fertility rate per woman & 3.0 & 2.2 & 2.97 & 3.7 & 2.96 & 3.1 \\
\hline$\%$ of one-year-old children vaccinated for measles & $83 \%$ & - & $96 \%$ & $95 \%$ & $96 \%$ & $98 \%$ \\
\hline Married women using some form of contraception & - & - & $59.2 \%$ & $56 \%$ & $53.7 \%$ & - \\
\hline No. of hospital beds per 1000 population & 2.2 & 2.0 & 2.0 & 1.8 & 3.7 & 1.8 \\
\hline No. of physicians per 1000 population & 2.1 & 1.9 & 0.6 & 2.3 & 1.2 & 1.6 \\
\hline No. of nurses and midwives per 1000 population & 4.1 & 4 & 1.3 & 3.0 & 4.8 & 3.7 \\
\hline
\end{tabular}

$\mathrm{GDP}=$ gross domestic product

aThe data reported in this table cover years 2003-2009 and are not for the same year in each of the columns or the rows. These data are reported only to provide a comparative context for Saudi Arabia.

Most recent estimates indicate that $32 \%$ of the population is under 15 years of age, and half of the population is younger than 25.3 years. Only $2.8 \%$ of the population is 65 or older (WHO 2010a; MOH 2009). Life expectancy at birth increased from 53.9 years in 1970-1975 to 73.4 years in 2008. Infant mortality decreased from a high of 118 deaths per 1,000 live births in 1985 to 19.1 in 2000. In 2009 Saudi Arabia experienced 19.3 births and 3.3 deaths per 1,000 population.

In 2008, 37\% of men and 6\% of women above age 15 were smokers (UNDP 2010; WHO Regional Health Systems Observatory: Eastern Mediterranean Region Office [EMRO] 2006; WHO 2010a, 2011; World Bank 2010). The average daily caloric intake of a Saudi in 1995 was 3,128 calories or more (Madani et al. 2000). The inactivity rate among men and women is estimated at $43.3 \%$ and $99.5 \%$, respectively (Al-Hazzaa 2004). These lifestyles have led to obesity rates of $29.5 \%$ in men and $43.5 \%$ in women (WHO 2010b). 


\section{Ranking on Various Development Indicators}

The World Health Organization's comparative assessment of healthcare systems in its 191 member states ranked Saudi Arabia 26th on overall performance, 61st on goal attainment, 58th on the basis of Disability Adjusted Life Expectancy and 63rd in health expenditures per capita in international dollars in 1997 (WHO 2000). With a life expectancy at birth of 72.7 years in 2007, Saudi Arabia was ranked 75th in the world by the UNDP (2009), and with an estimated adult literacy rate of $85 \%$ in the same year the country ranked 88th. The female literacy rate in 2007 was $79.4 \%$, compared with $89.1 \%$ for males. In the same year, Saudi Arabia ranked 68th on the proportion of population having access to improved water sources $(90 \%)$ and 75 th for the percentage of children under five years of age who were underweight for age (14\%).

Out of 182 countries with comparable data, Saudi Arabia was ranked 59th on the composite Human Development Index (HDI) (UNDP 2009), a comparative measure of human well-being based on life expectancy, adult literacy and standard of living. Saudi Arabia's score on the HDI rose by $1 \%$ per year from 0.556 in 1980 to 0.752 in 2010 . The country ranked 128 th on the Gender Inequality Index and 63rd on the Corruption Perception Index in 2008.

\section{Origins, History and Evolution}

The origins of the Saudi healthcare system can be traced to 1926, with the establishment of a Health Directorate in Jeddah and the opening of Ajyad hospital in Mecca and Bab Shareef hospital in Jeddah. Prior to these developments, there was no organized healthcare system in the country. A year later, the Directorate was renamed the Directorate of General Health and Ambulances, and in 1951 the Directorate finally became the Ministry of Health (WHO-EMRO 2006). By this time, the Ministry operated 11 hospitals and 25 dispensaries in various parts of the country. For the next decade, however, the Ministry was strapped for resources, including an acute shortage of healthcare professionals. But in the ten years between 1966 and 1976, a remarkable 40-fold increase in oil revenues led to much greater capital investment in healthcare infrastructure. By 1970 the country had 74 hospitals with a total of 9,039 beds, and by 2002 there were 331 hospitals with 47,242 beds (Metz 1992; MOH 1999; WHO-EMRO 2006).

Progress in workforce development, however, remained slow. The first Saudi physician graduated in 1951 from a medical school in Egypt. As recently as 1970, there were only 1,172 physicians and 3,267 nurses in the country - almost all of them foreigners. In the last two decades, serious efforts have been made to rapidly increase the supply of Saudi healthcare workers. Consequently, by 1997 , close to 2500 Saudi students were enrolled in medical schools at home or overseas (Metz 1992; MOH 1999; WHO-EMRO 2006).

Planning for a countrywide healthcare system began in 1971 with the development of successive five-year national health plans. The real expansion of the healthcare system, however, occurred between 1980 and 1990, when a large number of hospitals and primary health centres (PHCs) were built. For example, in the three-year period between 1985 and 1987, 65 new hospitals and 312 new PHCs were established. The rate of growth slowed in the 1990s because of a relatively flat $\mathrm{MOH}$ budget that resulted in the suspension of plans for some large projects such as the King Fahad Medical City in Riyadh. The 1990s also saw notable growth in the private health sector which, by the end of the decade, accounted for approximately $15 \%$ to $20 \%$ of all healthcare visits and $19 \%$ of all hospital beds, and employed $28 \%$ of physicians and $19 \%$ of nurses in the country $(\mathrm{MOH}$ 1999; WHO-EMRO 2006).

In the twenty-first century, the number of healthcare facilities has continued to grow. According to $\mathrm{MOH}$ data for 2009, altogether there were 408 hospitals in the country (with a total of 55,932 beds); 244 belonged to the Ministry, 39 belonged to other governmental entities, and the remaining 125 were in the private sector. Currently, the Ministry operates $63 \%$ of all hospitals in the country. Of the remaining $37 \%$, the private sector operates $13 \%$, the Ministry of Defense and Aviation $8 \%$, the Ministry of Education 7\%, the National Guard 3\% and all other governmental entities combined 6\%. 
In the wake of the 1978 Alam Ata conference, the Saudi government bought into the concept of a three-tiered healthcare system in which community-based PHCs serve as a vehicle to achieve universal access (Al-Ahmadi and Roland 2005). As a result, the process of integrating the fragmented healthcare system was begun in 1980 (Al-Yousuf et al. 2002). Since then, significant progress has been made by the Saudi government to provide universal health coverage. The role of rural PHCs has been critical in this regard though services in some remote corners of the Kingdom are still quite limited. Expansion of the primary care system continued at a fast pace in the first decade of the twenty-first century. In 2009 the MOH operated 1925 PHCs in the 13 geographic regions of the country.

The PHCs vary in size and allocation of resources as well as the number of people served which can range from 500 to 25,000 individuals. These gender-separated clinics account for more than $80 \%$ of visits to public sector facilities. The average catchment population for a PHC in 2002 was about 11,889 (MOH 2003). Many PHCs, however, are overburdened and serve a population of as many as 100,000 . Also, there is considerable regional variation in the number of facilities per 100,000 population as well as the spectrum of services offered in each PHC.

\section{Components of the Healthcare System}

Conceptually, the publicly financed healthcare system is modelled after the National Health Service in the United Kingdom. Though a robust private sector has emerged over the years, the defining feature of the Saudi health system remains its oil-revenue-funded public sector and centralized planning (Al-Yousuf et al. 2002). For administrative purposes, the 13 geographic regions of the country are divided into 19 health regions, each with its own Regional Directorate of Health (Al-Yousuf et al. 2002). The Ministry of Health (MOH) is responsible for planning, implementation and regulation of health services, with considerable operational autonomy afforded to the 19 health regions. Aside from the financing and delivery of care, the $\mathrm{MOH}$ exercises considerable regulatory authority, including price control for services rendered in the private sector as well as the price of medical devices and pharmaceutical products (Walston et al. 2008; Al-Yousuf et al. 2002).

The $\mathrm{MOH}$ is the pre-eminent provider of all ambulatory and inpatient care. Services including emergency care, elective care, dialysis, organ transplants, open-heart surgery and all forms of cancer treatment are available to Saudi nationals largely free of charge (Metz 1992; WHO-EMRO 2006). The situation, however, is more complicated for the 6.3 million foreign workers and their dependents. With the exception of those employed in the public sector, a vast majority of foreign workers and their dependents are expected to receive care in the private sector through employment-based insurance, self-paid insurance or as an entirely out-of-pocket expense (Oxford Business Group 2010).

The private sector with its 11,833 beds in 125 hospitals, 217 clinics, and 17,148 physicians (MOH 2009) is almost entirely for-profit and operates on the basis of fee for service, whether paid for by the employer, insurer, or out of pocket. Some components of the healthcare system are part of various other ministries (Walston et al. 2008; WHO-EMRO 2006). For example, the Saudi Arabian National Guard operates 60 primary or secondary health centres and four hospitals, with more than 1,400 beds in different parts of the country. The Ministry of Defense and Aviation operates another ten hospitals with approximately 3,500 beds. Services at these establishments are available only to employees of these ministries and their families.

Additionally, there are four autonomous or semi-autonomous, government-owned, large specialty hospitals in Riyadh and Jeddah. These facilities include the King Khalid University Hospital, King Faisal Specialist Hospital and Research Centre, and King Khalid Eye Specialist Hospital (Al-Yousuf et al. 2002; Walston et al. 2008). Some of the private hospitals such as Soliman Fakeeh Hospital in Jeddah and the ARAMCO hospital in Dahran are among the largest in the country and serve the employees and dependents of mostly non-Saudi workers in the private sector.

In 1993, the Saudi Commission for Health Specialties was created to supervise, regulate and accredit all health-related training programs in Saudi Arabia. The Commission is also authorized to issue and renew licences for various cadres of healthcare professionals. 


\section{Trends in Healthcare Financing}

Some summary statistics on healthcare financing in Saudi Arabia are shown in Table 2. As mentioned earlier, the public sector, which owns most of the facilities and provides the bulk of services in the country, is funded through oil revenues. WHO statistics for 2008 indicate that the country spent US\$621 per person on healthcare, of which $77.6 \%$ was paid for by the government and $16.3 \%$ was an out-of-pocket expenditure (WHO 2010a). The Ministry of Health estimates that of the total private sector spending on health, $68 \%$ is paid for by the employer in the form of health insurance premiums, direct payments to providers or cost of services provided at company-owned facilities. In 2010, Saudi Arabia allocated US $\$ 16.3$ billion (11.3\% of the national budget) for health and social services. This translated into a $51 \%$ increase over the previous year's allocation of US $\$ 10.7$ billion (8.5\% of the national budget) (Saudi Gazette 2010).

\section{Table 2. National spending on healthcare ${ }^{2}$}

\begin{tabular}{|l|c|c|c|c|c|}
\hline & $\mathbf{1 9 9 7}$ & $\mathbf{2 0 0 0}$ & $\mathbf{2 0 0 6}$ & $\mathbf{2 0 0 7}$ & $\mathbf{2 0 0 8}$ \\
\hline Health expenditure as \% of GDP & $3.5 \%$ & $4.3 \%$ & $3.3 \%$ & $3.4 \%$ & $3.6 \%$ \\
\hline Government spending on health as \% of total health spending & $80.2 \%$ & $71.6 \%$ & $77 \%$ & $\mathbf{7 9 . 5} \%$ & $68.2 \%$ \\
\hline Private sector spending on health as \% of total health spending & $19.8 \%$ & $28.4 \%$ & $23 \%$ & $20.5 \%$ & $31.8 \%$ \\
\hline Government spending on health as \% of total government spending & $9.4 \%$ & $9.2 \%$ & $8.7 \%$ & $8.4 \%$ & $8.4 \%$ \\
\hline Per capita government spending on health in US\$ & - & 276 & 379 & 422 & 461 \\
\hline Per capita government spending on health in PPP\$ & 297 & 520 & 559 & 610 & 567 \\
\hline Per capita total spending on health in US\$ & 260 & 386 & 492 & 531 & 676 \\
\hline Per capita total spending on health in PPP\$ & 332 & 726 & 720 & 768 & 831 \\
\hline
\end{tabular}

$\mathrm{GDP}=$ gross domestic product; $\mathrm{PPP}=$ purchasing power parity.

aFrom World Health Report 2000, WHO.

There has also been a rapid growth in the health insurance business, which increased by $57 \%$ in 2008 to a total of US\$1.2 billion, compared with US\$826 million in 2007 (Saudi Gazette 2010). In terms of market share, health insurance represented $44 \%$ of the insurance market in 2008 (Alkahtani 2008; Saudi Gazette 2010).

\section{Workforce Growth and Development}

As with all other sectors of the economy, most healthcare workers, including physicians, nurses and pharmacists, are expatriates from Egypt, the Philippines, Pakistan, India, Bangladesh and many other countries. A significant number of Europeans, Australians, Canadians and Americans are also among the vast array of healthcare providers. Altogether, there were 55,284 physicians and 110,858 nurses in the country in 2009 , of which $70 \%$ and $79 \%$ worked in the public sector. In the same year, only $23.1 \%$ of physicians and $32.3 \%$ of nurses in the country were Saudi nationals. The total number of physicians employed by the $\mathrm{MOH}$ was 25,832 , and of those only $22.6 \%$ were Saudi nationals, whereas a total of 63,297 nurses were employed by the $\mathrm{MOH}$, and of those $50.3 \%$ were Saudi nationals. Interestingly, of the 17,148 physicians and 23, 308 nurses in the private sector, only $4.9 \%$ and $4.8 \%$ respectively were Saudi nationals (MOH 2009).

Continuing efforts have been made since the late 1950s to provide training opportunities locally and abroad for Saudi nationals to become healthcare professionals. Training for male nurses' aides began at the first Health Institute in 1958. Currently there are many Health Institutes and Junior Colleges operated by the $\mathrm{MOH}$ for high school graduates to receive a diploma in nursing. 
Concurrently, the Ministry of Higher Education operates a number of Bachelor of Science in Nursing (BSN) and Master of Science in Nursing (MSN) programs. Recent data indicate that $67 \%$ of Saudi nurses were trained at a Health Institute and 30\% graduated from a Junior College. Only $3 \%$ of Saudi nurses graduated from BSN programs (Aldossary et al. 2008). A number of private schools of nursing have emerged in the last 10 to 15 years.

Whereas just ten years ago there were only five medical schools in the country, now there are 21, with six more in various stages of development. Five of the medical schools are private and sixteen are government owned (MOH 2009). Despite their average tuition of US $\$ 15,000$ per year, the number of private medical schools is likely to increase in the coming years. Additionally, hundreds of Saudi men and women are enrolled on government scholarships in medical schools in more than a dozen countries in Europe, Asia and North America. A number of programs in Saudi universities and vocational institutions also offer training and education in health-related professions, including a Master's degree in Health Administration.

\section{Quality of Care}

Since 1993 there has been a concerted effort to improve the quality of healthcare by developing appropriate referral systems, improving healthcare-provider training, accrediting facilities and emphasizing evidence-based medicine (EBM). However, there continues to be wide variation in access, effectiveness and outcomes of care in various settings (Al-Ahmadi and Roland 2005). Previous studies have raised questions about the quality of care for common conditions such as acute respiratory disorders, diabetes, hypertension, mental disorders and asthma (Al-Khaldi et al. 2002; Al-Khaldi and Al-Sharif 2002; Al-Mustafa and Abularhi 2003; Siddiqui et al. 2001). There are also reports of overprescribing by physicians - a practice attributed to the availability of medicines free of charge to all Saudi nationals (Dashash and Mukhtar 2003; El-Gilany 2000; Mahfouz et al. 1997).

According to one study, $85 \%$ of patients visiting PHCs received 1.4 drugs per prescription, and $87 \%$ of prescriptions for acute respiratory disorders included antibiotics (El-Gilany 2000). Generally, care provided at public sector facilities and particularly at hospitals and PHCs owned by the MOH is perceived as inferior to private sector care. Consequently, $80 \%$ of care provided in the private sector is to Saudi nationals (Walston et al. 2008). Since most studies on the quality of care have been conducted in $\mathrm{MOH}$ facilities, little information is available regarding the quality of care in the private sector.

There is an expressed desire in the higher echelons of the establishment to implement EBM. Guidelines for some common conditions have been established, but their implementation remains sporadic because of a lack of dissemination of information and limited interest or access to medical journals. Consequently, management of conditions for which standardized guidelines and protocols are available continues to show a wide variation (Al-Khashman 2001; Al-Faris and Al-Taweel 1999; Dashash and Mukhtar 2003). Surveys of patients and providers point to high levels of dissatisfaction in both groups. It appears that some of the dissatisfaction stems from language barriers and communication problems between patients and providers, $80 \%$ of whom in primary care settings are non-Saudi (Al-Khaldi et al. 2002; Al-Yousuf et al. 2002; Mansour and Al-Osimy 1993).

Other factors such as high staff turnover rates, lack of communication and coordination among healthcare facilities, and stressful work environment also contribute to high levels of dissatisfaction. Studies on this subject have also noted problems related to a lack of management training and postgraduate qualifications among technical supervisors and mid-level regional managers (Jarallah and Khoja 1998). In turn, managers point toward a lack of decision-making authority, inadequate information and confusion regarding the chain of command as the sources of managerial deficiencies. Overall, efforts to improve quality of care remain fragmented and uncoordinated (Al-Ahmadi and Roland 2005).

\section{Recent Developments}

Since the inception of the healthcare system in the second quarter of the twentieth century, the financial burden of meeting the healthcare needs of all Saudis and many foreign workers had been shouldered almost entirely by the government. Historically, the government neither levied taxes nor 
user fees for primary, secondary or even tertiary care, with the exception of some non-binding user fees at specialty hospitals (Metz 1992; WHO-EMRO 2006; Walston et al. 2008).

Over time, policy makers came to realize that the existing model of healthcare financing and delivery was neither efficient nor sustainable. Regardless of the question whether Saudi oil reserves will be depleted in 50,100 or 200 years, the need to introduce third-party payment mechanisms and some form of cost shifting to influence both consumer and provider behaviour was seen as independently compelling. Consequently, far-reaching policy changes have been introduced in the last ten years. The most important of these has been the introduction of nationwide health insurance. This has also led to a major shift in the role of the government and particularly that of the $\mathrm{MOH}$, from a provider and payer of services to that of a regulator and overseer.

To make a transition from a welfare-oriented National Health Service model to a National Health Insurance model, the government has adopted a phased approach. The first step was the passage of the Cooperative Health Insurance Act of 2003 (promulgated in the Royal Decree \# M/10 issued on August 1999). The seeds of the Act, however, were sown in the 1991 recommendation of a steering committee to have all employers insure their employees (Alkahtani 2008). In phase one, which was started on July 15, 2006, the Act required, in three stages, all employers in the private sector to purchase comprehensive health insurance for their Saudi and foreign employees and their dependents for the full duration of their employment prior to the issuance of travel documents or residence permit by the government (Alkahtani 2008; Saudi Gazette 2010). According to the 4th annual report of the Council of Cooperative Health Insurance (CCHI), considerable progress has been made in implementation of the Cooperative Health Insurance Act, with 26 registered health insurance companies and 8.4 million insured individuals, of whom 6.47 million are expatriates and 1.87 million are Saudi nationals (CCHI 2010).

In phase two of the mandate, health insurance is to be extended to all public sector employees. The proposed changes in the system also require a change in the role of the $\mathrm{MOH}$ from healthcare delivery to mostly prevention, standardization and supervision. The new model requires divesting most of the public sector hospitals to the private sector through sale or rental (Walston et al. 2008). Details of these arrangements are still being worked out, and the picture remains quite murky at this stage. Consequently, the future of all PHCs as well as the timeline for divesting publicly owned hospitals remains unclear. At the completion of the process it is anticipated that, with few exceptions such as the armed forces, everyone in the country will have employer-sponsored health insurance. It should be noted that there have been many challenges in the implementation of the Cooperative Health Insurance Act, and progress has been slower than anticipated. Most of the challenges in implementation are attributed to a weak infrastructure, rising insurance premiums and insurance fraud (Alkahtani 2008).

\section{Strengths of the System}

In the last 50 years, Saudi Arabia has made impressive strides in developing the healthcare infrastructure. For a country that had no schools until 1937, no school for girls until 1961, and no medical school until 1969, it is quite remarkable that Saudi Arabia had more than 36,000 university students by 1978 . The country now boasts a large number of facilities with advanced technologies and highly trained professionals with the ability to provide sophisticated services such as open heart surgery and organ transplants. A Royal Decree issued in 2002 (the National Health Law of 2003) requires "provision of comprehensive health services to all inhabitants in Saudi Arabia in an equitable, affordable and organized manner" (WHO-EMRO 2006).

The emphasis on PHCs to ensure universal access, adoption of the essential drugs formulary, development of a referral system from primary- to secondary- and tertiary-level facilities, better record keeping, and implementation of accreditation and licensing requirements has allowed demonstrable improvements in efficiency and quality of care. Over the last three or four decades, there has also been a steady improvement in population health indicators such as life expectancy at birth, immunization rates, incidence of infectious diseases and infant and maternal mortality rates (MOH 2009; WHO 2000, 2010a; WHO-EMRO 2006). 
Under the regulatory authority of the Saudi Commission for Health Specialties (SCHS), which was created in 1992, a number of advanced training programs in clinical disciplines such as surgery, medicine, pediatrics, obstetrics and gynecology, and cardiology are available. Twenty-eight specialty boards and 97 different training programs including fellowship, certification and diploma programs are accredited by the Commission. With 21 medical schools - 16 governmental and five private (MOH 2009) - and many more students enjoying training opportunities overseas, there is an emerging critical mass of highly trained clinicians and scientists to reduce the country's dependence on foreign physicians. Likewise, the number of locally trained nurses, although smaller than locally trained physicians, will grow to significant proportions by the end of this decade. Training opportunities at many institutions for other cadres of health-related professions such as pharmacists, physical therapists, and lab technicians are also available.

In the last two decades, clinical and basic science research has gained a lot of momentum, and more than a dozen medical journals are being published. Despite considerable variation across the journals in the quality and regularity of publication, many first-rate articles are contributed by Saudi biomedical researchers. A cursory examination of these journals indicates that many articles are based on descriptive analysis of survey data on satisfaction, opinion polls of various patient and provider groups, or quality, delivery, and distribution of services. Blind clinical trials and basic science research is still very scant among the array of articles published every year. The Annals of Saudi Medicine and the Saudi Medical Journal are the most regular and widely circulated.

Saudi Arabia has also developed a strong biotechnology research infrastructure, which includes business ventures such as Jeddah BioCity. A story printed on July 8, 2002, in the newspaper USA Today reported plans to establish a research centre for stem cell research, including therapeutic cloning research, at King Faisal Specialist Hospital and Research Center (Friend 2002). Another example is the King Abdul Aziz City for Science and Technology, which spent 185.9 million Saudi Riyals ( $\sim$ US\$ 60 million) on 430 medical research projects between 1979 and 2004 (Alabdula'aly 2004). The foremost example of vast financial investments in scientific and technological research is the King Abdulla University of Science and Technology (KAUST), established in 2009 with an initial endowment of US $\$ 10$ billion. In recent years there has also been a lot of push for investment in health informatics and electronic medical records (Altuwaijri 2010).

\section{Issues and Concerns}

Like several of its neighbours (see Table 1 for comparative data) and middle-income developing countries worldwide, Saudi Arabia is in the middle of transitioning from a society that had high birth and mortality rates, a relatively short life expectancy and high prevalence of communicable disease to a society characterized by low mortality rates, longer life expectancy and high prevalence of chronic disorders (Al-Yousuf et al. 2002). Typically, in this stage of the epidemiologic transition most countries experience rapid population growth due to the continuation of high birth rates, while mortality rates decline more quickly and life expectancy increases by several years. In the transitional period such countries also experience the dual impact of communicable diseases and rising levels of chronic conditions such as heart and lung disorders, diabetes, cancer, obesity and arthritic problems. Already, as a result of a sedentary lifestyle among $43.3 \%$ of men and $99.5 \%$ of women, obesity rates of $29.5 \%$ in men and $43.5 \%$ in women, and smoking rates of $37 \%$ in men and 6\% among women (WHO 2010a), cardiovascular problems have risen to epidemic proportions. These demographic, lifestyle and morbidity changes translate into a burgeoning demand for health services (Al-Yousuf et al. 2002).

Traffic injuries are among the most common causes of death in Saudi Arabia. According to the WHO, Saudi Arabia has one of the highest road-accident mortality rates in the world, with 29 deaths per 100,000 population (WHO 2010a). Ansari et al. (2000) have reported that $81 \%$ of deaths and $20 \%$ of bed occupancy in MOH hospitals are due to traffic accidents. The Saudi General Directorate of Traffic has reported that with more than 36,000 injuries and a death toll of 6,485 in 2008-2009, about 17 people die in road accidents every day (Rasooldeen 2010). Traffic injuries 
are now the principal cause of death for Saudi men between the ages of 16 and 36. Another media report suggested that one third of all hospital beds in the county are occupied by victims of road accidents, with an estimated annual cost of SR26 billion (US\$ 7 billion) (Baxter 2010). Since high levels of injury and death from automobile accidents are likely to continue in the foreseeable future, the need for high-cost emergency and trauma services will also continue to increase at a fast pace.

The pharmaceutical industry in Saudi Arabia grew by 9\% in 2009 and is one of the fastest growing sectors of the economy, with annual sales approaching US\$1.3 billion (Saudi Gazette 2010). Previous reports have suggested that Saudi Arabia represents US $\$ 1.7$ billion (65\%) of the US\$2.7 billion pharmaceutical market comprising the Gulf Cooperation Council (GCC) member countries (Hawarey 2008). More than $82 \%$ of drugs used in the GCC market are imported from other countries (Bains 2009). Generic drugs reportedly constitute only about $20 \%$ of this market. Other estimates suggest that the generic drug market is only around $5.8 \%$ of the total pharmaceutical market (Bains 2009).

The regulatory mechanisms governing pharmacies and pharmaceutical products are minimally implemented and were largely designed to put Saudi nationals in control of the retail and wholesale distributive channels (Issa et al. 2009). In practice, pharmacies are largely unregulated. With the exception of narcotics, almost all other medicinal products, whether traditional, herbal or allopathic, are sold over the counter with or without a doctor's prescription. Many pharmaceutical products, including antibiotics, are counterfeits produced in China, India, Pakistan and many other countries including Saudi Arabia itself. Some estimates suggest that " $30-40 \%$ of the pharmaceuticals sold at pharmacies and hospitals in Saudi Arabia are counterfeit" (Al-Iryani and Ba-Swaid 2008).

Because of the widely perceived religious prohibitions against contraception and the political ramifications of such policy decisions, there is no department of family planning. Pills and condoms are available over the counter in most pharmacies, but the frequency of their use, in the absence of reliable data, is a matter of conjecture. According to the WHO (2010a), the contraceptive use rate by any method among married women between the ages of 15 and 49 in the 1990-2008 period was only $23.8 \%$. Contraceptive measures such as intrauterine devices and tubal ligations are not commonly provided upon request in the public sector. Abortions are strictly prohibited unless indicated to save the life of a pregnant woman. Due to the perceptions of men regarding masculinity and virility as well as concerns about the irreversibility of the procedure, vasectomies are practically unheard of. Since the locus of control regarding important decisions including contraception and family size resides mostly with men, population growth is likely to continue at a relatively fast rate in the foreseeable future. Allegedly, Saudi Arabia has one of the highest in vitro fertilization birth rates in the world, with about $4 \%$ of births every year resulting through this technology compared with $1 \%$ of births in the United States (Friend 2002).

Because of a lack of inter-agency and inter-sectoral cooperation, there are widespread economic and operational inefficiencies. Duplication, waste and bureaucratic hurdles are directly linked to various branches of the government vying for greater influence and flagship status. In the past, salary differentials of $200 \%$ to $300 \%$ among employees of various agencies were not uncommon. For example, physicians and nurses working for the $\mathrm{MOH}$ earned salaries that were often half or one third of the salaries of their counterparts at the National Guard (Walston et al. 2008). More importantly, salary inequities within the same agency based on the employees' country of origin have been a common source of discontent for foreign workers. A Royal Decree of limited scope issued in May 2010 attempted to address the issue of salary inequity by seeking to standardize public sector salaries. However, in the absence of comprehensive reforms, widespread inequities are likely to continue in the foreseeable future.

Despite the establishment of thousands of PHCs throughout the country, the system is heavily slanted in favour of resource-intensive episodic care provided at secondary- and tertiary-level medical centres. Though a referral system has existed since 1986 and guidelines for quality assurance in primary care have been in place since 1993 (Al-Ahmadi and Roland 2005), referrals from PHCs to general and specialty hospitals remain low, and the exchange of information between primary 
and higher-level facilities takes place for only about one quarter to one third of patients (Khattab et al. 1999; Khoja et al. 1997). Further, healthcare facilities in urban centres such as Riyadh, Jeddah and Dammam attract most of the economic and human resources. As such, with the availability of secondary and tertiary hospitals in the same vicinity, patients in these densely populated urban centres tend to bypass the primary care centre in favour of a secondary- or tertiary-level hospital. The impact of such utilization patterns is not only an excessive burden on the hospital emergency departments and underutilization of PHCs but also significantly greater cost of care.

Similar to the policies officially or unofficially adopted in the neighbouring countries (e.g., "Kuwaitization," "Omanization" and "Emiratization"), Saudi Arabia officially adopted the policy of "Saudization" in the 2004 development plan. Unofficially, the policy had been in practice for many years. Regrettably, this policy has had many unintended and undesirable effects. For example, the policy often results in the appointment and promotion of Saudi nationals without sufficient qualifications or experience to key positions. Since the number of trained Saudi health administrators is a miniscule in proportion to the number of available positions, most senior administrative positions are filled by physician or non-physician Saudi nationals with little or no management experience. Another example stems from Saudi women's unwillingness to work evening and night shifts. Consequently, many foreign workers are scheduled in an openly discriminatory fashion to "graveyard" shifts. Not surprisingly, high levels of stress, dissatisfaction and low self-esteem linked to a perceived lack of appreciation, patient overload, cultural differences and discriminatory practices have been reported among primary care physicians of foreign origins (Al-Shammari et al. 1995).

\section{Future Direction}

The Cooperative Health Insurance initiative designed to address concerns about the long-term financing and sustainability of the health care system has been outlined above. Suffice it to say that the UK-style National Health Service model in Saudi Arabia is rapidly giving way to a US-style free market system in which employment-based insurance will be the dominant financing mechanism, with the bulk of services provided in the private sector. These changes indicate a 180 -degree turn in the philosophic and structural principles of the healthcare system.

In the transitional period, the Saudi system will simultaneously have elements of both a welfare system and a free market enterprise. Before the divestiture of facilities owned by the $\mathrm{MOH}$ and the implementation of health insurance for the public sector employees and their dependents, a large number of people will continue to enjoy the benefits of a National Health Service model. Those in the private sector, however, will be diverted to privately delivered care through employment-based insurance.

With the shift in the mechanisms of healthcare financing and delivery, the Saudi system is likely to not only acquire many of the features of the US healthcare system but encounter similar difficulties as well. If market forces exert similar pressures in Saudi Arabia as they have in the US, it would not be surprising to see rising costs and reduced access becoming serious problems in the coming years. On the positive side, third-party payers will likely exercise financial leverage in demanding operational efficiencies and superior quality of care from the private healthcare providers. On the negative side, however, insurance companies may also resort in the coming years to risk reduction strategies such as denial of coverage to patients with pre-existing conditions, high co-pays and deductibles, and requirement of preauthorization for expensive tests and procedures.

In the event such practices become common, many patients will experience reduced access to adequate services in a timely fashion. Such a scenario would inevitably result in a call for greater regulation and governmental intervention. Already, financial indicators such as steadily increasing insurance premiums in the tune of 5\% to 10\% are becoming a source of concern (Alkahtani 2008). To avoid the possibility of such threats becoming a reality, the Saudi government can learn from the US experience. The development of robust regulatory mechanisms and a vigorous exercise of the regulatory authority of the Council of Cooperative Health Insurance would go a long way in forestalling these problems.

In addition to restructuring the healthcare financing and delivery mechanisms, the problem of 
population growth will have to be addressed. Despite the spectre of a confrontation with the religious orthodoxy, the country simply cannot avoid having to deal with the challenge of a ballooning population. The current hands-off approach in the public sector, which does not allow active promotion of contraception, will have to be reconsidered. Some family planning services and contraception education will be necessary under the auspices of the $\mathrm{MOH}$ in the foreseeable future.

The prospects and implications of the "Saudization" policy must also be carefully examined in the context of demand and supply of health workers. With the projected growth of the population to 30 million by 2016 and an increase in the number of "old" people from 1 million to 2.5 million by 2020 (Booz \& Company Inc. 2007), the country will need an additional 15,000 to 20,000 hospital beds and nearly 15,000 more physicians. At the projected production levels of Saudi doctors and nurses, the prospects of meeting that demand without importing foreign workers is virtually zero.

It is important to note that most Saudi health workers are currently employed in the public sector. With the planned divestiture of publicly owned facilities, the Saudis presently employed in the public sector will have to compete with non-Saudis in the rapidly growing private sector. In a competitive market place, it seems likely that many of the new jobs in the private sector will be filled by non-Saudi health workers who are willing to work at lower salaries.

\section{Conclusions}

Given that until about the middle of the twentieth century little existed in the way of an organized healthcare system, it must be acknowledged that Saudi Arabia has made impressive strides in developing the healthcare infrastructure. In the span of half a century a number of universities and research institutions, hundreds of hospitals, and thousands of primary care centres have been established. Dozens of training programs are in place to train various cadres of healthcare workers. The Saudi experience as well as that of other Gulf States such as Kuwait, Qatar, Oman and UAE demonstrates that, with generous financial support, it is not difficult to erect modern facilities and fill them with internationally recruited personnel capable of providing first-rate clinical care. The challenge, however, is to make the system efficient and sustainable.

The transition from a welfare-oriented National Health Service model to an employer-financed private delivery model is fraught with uncertainty and challenges. Saudi Arabia, therefore, would be wise to learn some lessons from the escalating cost crises and lack of access to healthcare for millions in the US. There are already indications that the Saudi government plans to maintain a strong regulatory function, including mechanisms for price control.

Despite the availability of a number of public and private training programs, self-sufficiency in the supply of physicians, nurses and allied health professionals will not occur in the foreseeable future. Given the projected reliance on foreign workers to meet the healthcare needs of its citizens, the country will need to reconsider the policy of "Saudization." To successfully make the transition to a twenty-first century meritocratic society, it is important to offer the promise of assimilation and a long-term future. Finally, the challenges Saudi Arabia faces are neither unique nor insurmountable. With careful planning, implementation and adjustment of policies, there is plenty of reason for optimism and hope for the future.

\section{Notes}

${ }^{1}$ The data reported on demographic, socio-economic and health status indicators in this and other sections of the paper were obtained from a number of different sources including the Saudi Ministry of Health, the United Nations Development Program and the World Health Organization. For many of the indicators, there is variation in the data reported for the same period by different agencies. Therefore, these data should be used with caution.

${ }^{2}$ Most of the data in this table were obtained from the World Health Statistics reports issued by the WHO. As pointed out in the first note, there is variation in the data reported in various documents by the same or different agencies for the same year. For example, in World Health Statistics 2010, the "Total expenditure on health as \% of gross domestic product" in 2000 for Saudi Arabia is reported as 3.7\%, while in World Health Statistics 2011 the number reported for the same year is 4.3\%. In this table and the text, data from the 2011 report have been used. In using data from other sources at various places in the article, the author selected data from more recent sources in those instances where discrepancies between two or more sources were noted. 


\section{References}

Alabdula'aly, A.I. 2004. "Experience of King Abdul-Aziz City for Science and Technology in Funding Medical Research in Saudi Arabia.” Saudi Medical Journal 25(1 Suppl.): S8-12.

Al-Ahmadi, H. and M. Roland. 2005. "Quality of Primary Health Care in Saudi Arabia: A Comprehensive Review." International Journal for Quality in Health Care 17(4): 331-46.

Aldossary, A., A. While and L. Barriball. 2008. "Health Care and Nursing in Saudi Arabia." International Nursing Review 55(1): 125-8.

Al-Faris, E.A and A. Al-Taweel. 1999. "Audit of Prescribing Patterns in Saudi Primary Health Care: What Lessons Can Be Learned." Annals of Saudi Medicine 19(4): 317-21.

Al-Hazzaa, H. 2004. "Prevalence of Physical Inactivity in Saudi Arabia: A Brief Review.” Eastern Mediterranean Health Journal 10(4\&5): 663-70. Retrieved July 28, 2011. <http://62.193.78.3/Publications/EMHJ/1004_5/ $\mathrm{PDF} / 25 \% 20$ Prevalence\%20of\%20physical.pdf>.

Al-Iryani, A and H. Ba-Swaid. 2008, October 22. "Some 30-40\% of Medicines Sold Locally 'Are Counterfeit', Says Manufacturer.” Saudi Gazette. Retrieved July 21, 2011. <http://www.saudigazette.com.sa/index. cfm?method=home.regcon\&contentID=2008102219824>.

Alkahtani, A.A. 2008. "The Experience of Mandatory Health Insurance in Kingdom of Saudi Arabia." Presentation at BIA- Compulsory Medical Insurance Workshop. Retrieved March 28, 2012. <http://www. eventscom.net/bia/pr2.pdf .

Al-Khaldi, Y.M and A.I. Al-Sharif. 2002. "Availability of Resources of Diabetic Care in Primary Health Care Settings in Aseer Region, Saudi Arabia." Saudi Medical Journal 23(12): 1509-13.

Al-Khaldi, Y.M., M.Y. Khan and S.M. Khairallah. 2002. "Audit of Referral of Diabetic Patients to an Eye Clinic from a Primary Health Care Clinic.” Saudi Medical Journal 23(2): 177-81.

Al-Khashman, A.S. 2001. "Screening for Hypertension: Assessing the Knowledge, Attitudes, and Practice of Primary Health Physicians in Riyadh, Saudi Arabia.” Saudi Medical Journal 22(12): 1096-1100.

Al-Mustafa, B.A and H.A. Abularhi. 2003. "The Role of Primary Health Care Centers in Managing Hypertension: How Far Are They Involved?” Saudi Medical Journal 24(5): 460-5.

Al-Shammari, S., T. Khoja and A. Al-Subai. 1995. "Job Satisfaction and Occupational Stress among Primary Care Centre Doctors." International Journal of Mental Health 24: 85-95.

Altuwaijri, M.M. 2010. "Supporting the Saudi E-Health Initiative: The Master of Health Informatics Programme at KSAU-HS.” Eastern Mediterranean Health Journal 16(1): 119-24. Retrieved on July 27, 2011. <http://www.emro.who.int/Publications/EMHJ/1601/article20.htm>.

Al-Yousuf, M., T.M. Akerele and Y.Y. Al-Mazrou. 2002. "Organization of the Saudi Health System.” Eastern Mediterranean Health Journal 8(4\&5): 645-53.

Ansari, S., F. Akhdar, M. Mandoorah and K. Moutaery. 2000. "Causes and Effects of Road Traffic Accidents in Saudi Arabia." Public Health 114(1): 37-9.

Bains E. 2009. "Pharmaceuticals: Bringing in the Global Leaders.” Middle East Economic Digest 53(33): 14-20.

Baxter E. 2010, April 22. "Saudi Hospitals Struggling to Cope with Traffic Victims.” Retrieved May 12, 2010. <http://webcache.googleusercontent.com/search?q=cache:e2nEJpJnxs4J:www.arabianbusiness.com/saudihospitals-struggling-cope-with-traffic-victims-157591.html+Saudi+hospitals+struggling+to+cope+with+traffi $\mathrm{c}+$ victims \&cd=1\&hl=en\&ct=clnk\&gl=us\&source=www.google.com>.

Booz \& Company Inc. 2007. “The New Saudi Arabian Healthcare Market.” Retrieved March 28, 2012. http:// www.booz.com/me/home/what_we_think/40007409/40007869/42024629

Council of Cooperative Health Insurance - Saudi Arabia. 2010. 4th Annual Report. Retrieved August 3, 2011. $<$ http://www.cchi.gov.sa/en/Studies/Reports/AnnualReports/Pages/default.aspx>.

Dashash, N.A. and S.H. Mukhtar. 2003. "Prescribing for Asthmatic Children in Primary Health Care: Are We Following the Guidelines?” Saudi Medical Journal 24(5): 507-11.

El-Gilany, A.H. 2000. "Acute Respiratory Infections in Primary Health Care Centers in Northern Saudi Arabia." Saudi Medical Journal 6(5-6): 955-60.

Friend, T. 2002, July 8. "Saudis Take Lead on Stem-cell Cloning." USA Today. Retrieved July 28, 2011. <http:// www.usatoday.com/news/science/2002-07-09-arab-stemcell.htm>.

Hawarey, M. 2008, January 16. "The Kingdom Represents 65\% of GCC Pharmaceutical Market.” Business in Saudi Arabia Group. Retrieved March 28, 2012. <http://www.xing.com/net/business_ksa/general-businessdiscussion-49393/kingdom-represents-65-of-gcc-pharmaceutical-market-7256889/7256889/\#7256889>. 
Issa, A.N., M.I. Al-Ammar and S. Mostafa. 2009. Healthcare and Pharmaceutical Industries in Saudi Arabia - Member Briefing. American Health Lawyers Association. Retrieved July 21, 2011. <http://www.kslaw.com/ Library/publication/11-09\%20AHLA\%20Issa,\%20Al-Ammar,\%20Mostafa.pdf>.

Jarallah, J and T. Khoja. 1998. "Perceptions of Supervisors of Their Role in Primary Healthcare Programmes in Saudi Arabia." Eastern Mediterranean Health Journal 4(3): 530-8.

Khattab, M.S., M.A. Abolfotouh, Y.M. Al-Khaldi and M.Y. Khan. 1999. "Studying the Referral System in One Family Practice Center in Saudi Arabia." Annals of Saudi Medicine 19(2): 167-70.

Khoja, T.A.M., A.M. Al-Shehri, A.F. Abdul-Aziz and A. K.M.S. Aziz. 1997. "Patterns of Referral from Health Centers to Hospitals in Riyadh Region.” Eastern Mediterranean Health Journal 3(2): 236-43.

Madani, K.A., N.S. Al-Amoudi, and T. A. Kumosani. 2000. “The state of nutrition in Saudi Arabia." Nutrition and Health. 14(1): 17-31.

Mahfouz, A., A. Shehata, A. Mandil, A. Reda, G. Al-Erian, A.M. Al-Khuzayem and A. Kisah. 1997. "Prescribing Patterns at Primary Health Care Level in the Asir Region, Saudi Arabia: An Epidemiologic Study." Pharmacoepidemiology and Drug Safety 6(3): 197-201.

Mansour, A.A and M.H. Al-Osimy. 1993. "A Study of Satisfaction among Primary Health Care Patients in Saudi Arabia.” Journal of Community Health 18(3): 163-73.

Metz H.C. (ed.) 1992. Saudi Arabia: A Country Study. Washington, DC: Government Printing Office for the Library of Congress. Retrieved May 19, 2010. <http://countrystudies.us/saudi-arabia/>.

Ministry of Health - Saudi Arabia. 1999. Annual Health Report 1419/1420H. Riyadh: Ministry of Health.

Ministry of Health - Saudi Arabia. 2009. Statistical Book for 2009. Riyadh: Ministry of Health. Retrieved July 22, 201 <http://www.moh.gov.sa/en/Ministry/Statistics/Indicator/Pages/default.aspx>.

Oxford Business Group. 2010, May 12. "Saudi Health Care Drastically Changed; Balance Still Elusive." Saudi Gazette. Retrieved March 29, 2012. <http://www.saudigazette.com.sa/index.cfm?method=home.regcon\&cont entID $=2010040468331 \&$ archiveissuedate $=04 / 04 / 2010>$.

Rasooldeen, M.D. 2010, July 14. "Raising Awareness about Saher to Contain Accidents.” Arab News. Retrieved July 27, 2011. <http://arabnews.com/saudiarabia/article83709.ece>.

Siddiqui, S., D. Ogbeide, A. Karim, I. Al-Khalifa. 2001. "Hypertension Control in a Community Health Centre at Riyadh, Saudi Arabia." Saudi Medical Journal. 22(1):49-52.

United Nations Children's Fund. "Saudi Arabia: Statistics.” Retrieved July 22, 2011. <http://www.unicef.org/ infobycountry/saudiarabia_statistics.html>.

United Nations Development Program. 2003. Human Development Reports: National Report - Saudi Arabia 2003. Retrieved July 22, 2011. <http://hdr.undp.org/en/reports/national/arabstates/saudiarabia/Saudi\%20 Arabia_2003_en.pdf>.

United Nations Development Program. 2009. Human Development Report 2009: HDR 2009 Statistical Tables. Retrieved March 28, 2012. <http://hdr.undp.org/en/reports/global/hdr2009/>.

United Nations Development Program. 2010. Human Development Report: International Human Development Indicators. Retrieved July 22, 2011. <http://hdrstats.undp.org/en/countries/profiles/SAU.html>.

Walston, S., Y. Al-Harbi and B. Al-Omar. 2008. "The Changing Face of Healthcare in Saudi Arabia.” Annals of Saudi Medicine 28(4): 243-50.

World Bank. 2010. “Data: Saudi Arabia.” Retrieved August 13, 2011. <http://data.worldbank.org/country/ saudi-arabia>.

World Health Organization. 2000. World Health Report 2000. Retrieved August 13, 2011. <http://www.who. int/whr/2000/en/whr00_en.pdfs.

World Health Organization. 2010a. "Country Profiles: Saudi Arabia.” Retrieved July 22, 2011. <http://www. emro.who.int/emrinfo/index.aspx?Ctry=saa>.

World Health Organization. 2010b. World Health Statistics 2010. Retrieved August 2, 2011. <http://www.who. int/whosis/whostat/EN_WHS10_Full.pdf>.

World Health Organization. 2011. “Countries: Saudi Arabia: Statistics.” Retrieved July 22, 2011. <http:// www.who.int/countries/sau/en/>.

World Health Organization - Regional Health Systems Observatory: Eastern Mediterranean Region Office. 2006. "Health System Profile - Saudi Arabia." < http://gis.emro.who.int/HealthSystemObservatory/Profile/ Forms/frmProfileSelectionByCountry.aspx?CountryID=SAP000000000000000000\&CountryName=Sa udia\%20Arabia>. 